\title{
USOS DA TERRA SUJEITOS ÀS INUNDAÇÕES NA BACIA DE DRENAGEM DO RIO IMBÉ-URURAÍ, REGIÃO NORTE DO ESTADO DO RIO DE JANEIRO
}

\author{
Vinícius Santos Lima ${ }^{(a)}$, Carolina de Almeida Santos Cidade ${ }^{(b)}$, Sandra Baptista da Cunha $^{(c)}$ \\ (a) Doutorando do Programa de Pós-Graduação em Geografia da Universidade Federal Fluminense. \\ E-mail: vinicius_ahriman@hotmail.com \\ (b) Geógrafa pela Universidade Federal Fluminense - PUCG. \\ E-mail: carolacidade@gmail.com \\ (c) Professora Adjunta do Programa de Pós-Graduação em Geografia da Universidade Federal Fluminense. E- \\ mail: sandracunha@openlink.com.br
}

\section{Eixo: GEOGRAFIA FÍSICA E DESASTRES NATURAIS}

\begin{abstract}
RESUMO
Atualmente a geografia física aplicada têm produzido numerosos trabalhos acerca dos impactos causados por fenômenos naturais extremos. A maior parte das publicações, no âmbito das bacias de drenagem, têm se concentrado em ambiente urbanos, fato explicado pela presença antrópica e o seu potencial de intervenção sobre o meio físico. A despeito da importância nos estudos de bacias urbanas, objetivou-se aqui um estudo numa bacia rural, dividido em dois momentos. No primeiro, realizou-se o mapeamento do uso da terra utilizando o segundo nível taxonômico do Manual Técnico de Uso da Terra (IBGE). No segundo momento analisou-se as séries históricas de precipitação e as maiores manchas de inundação entre 1985 e 2015, identificando no ano de 2009 a maior ocorrência espacial deste fenômeno. Nesta fase também foi realizado o quantitativo dos usos da terra sujeitos as inundações, tendo como referência a maior mancha de inundação registrada na área de estudo.
\end{abstract}

Palavras-chaves: Uso da terra. Inundação. Rio Imbé-Ururaí

\section{INTRODUÇÃO}

A geografia física contemporânea tem recebido um grande quantitativo de publicações acerca de desastres naturais de distintas gêneses e processos, seja na produção de diagnósticos ou mesmo de prognósticos que buscam criar cenários futuros na prevenção desses fenômenos. No Brasil, a geomorfologia fluvial, em diálogo com demais áreas do conhecimento tem desenvolvido importantes trabalhos no campo analítico de bacias de drenagem e, as inundações, enquanto desastre natural que atinge variados usos da terra, têm recebido atenção de grande parte dos pesquisadores (SALGADO, et al., 2007; CUNHA E CUNHA, 2015; LIMA E COELHO, 2016)

Inundações são fenômenos de interesse em comum para a Universidade, Sociedade Civil e Poder Público (COELHO, 2008). Sua ocorrência pode levar a perdas materiais e até de vidas humanas. Compreender os processos condicionantes as inundações em bacias de drenagem urbanas e rurais têm sido um esforço por grande parte dos geógrafos brasileiros. A geomorfologia em diálogo com demais 
XVII Simpósio Brasileiro

de Geografia Fisica Aplicada

I Congresso Nacional

de Geografia Física

\section{OS DESAFIOS DA GEOGRAFIA FÍSICA NA FRONTEIRA DO CONHECIMENTO \\ Instituto de Geociências - Unicamp \\ Campinas - SP \\ 28 de Junho à 02 de Julho de 2017}

áreas, como as geotecnologias (SIG e SR) e a meteorologia vêm oferecendo suporte técnico ao ordenamento territorial-ambiental.

O acesso aos modernos Sistemas de Informações Geográficas (SIGs) e a utilização de produtos obtidos de sensores orbitais, como imagens multitemporais e dados interferométricos, tornou possível desenvolver diversos tipos de análises no âmbito dos estudos físicos (FLORENZANO, 2008).

A aplicação deste instrumental técnico no mapeamento das inundações e do uso da terra no estado do Rio de Janeiro é feito por órgãos oficiais, como o Instituto Estadual do Ambiente - INEA - e por pesquisadores vinculados a Instituições de Ensino Superior - IES -, com destaque ao Instituto Federal Fluminense, Universidade Federal Fluminense e Universidade Estadual do Norte Fluminense.

A despeito do razoável número de publicações sobre as inundações e dos usos da terra na região Norte do estado do Rio de Janeiro, foi Cidade (2016) quem primeiro quantificou as áreas dos diferentes usos da terra sujeitos às inundações na bacia de drenagem do rio Imbé-Ururaí.

A área de estudo (Figura 1) é uma sub-bacia do rio Paraíba do Sul, localizada em seu Baixo Curso. Para Lima (2014), suas áreas mais aplainadas são sazonalmente atingidas por inundações, fato também identificado por Miro (2009).

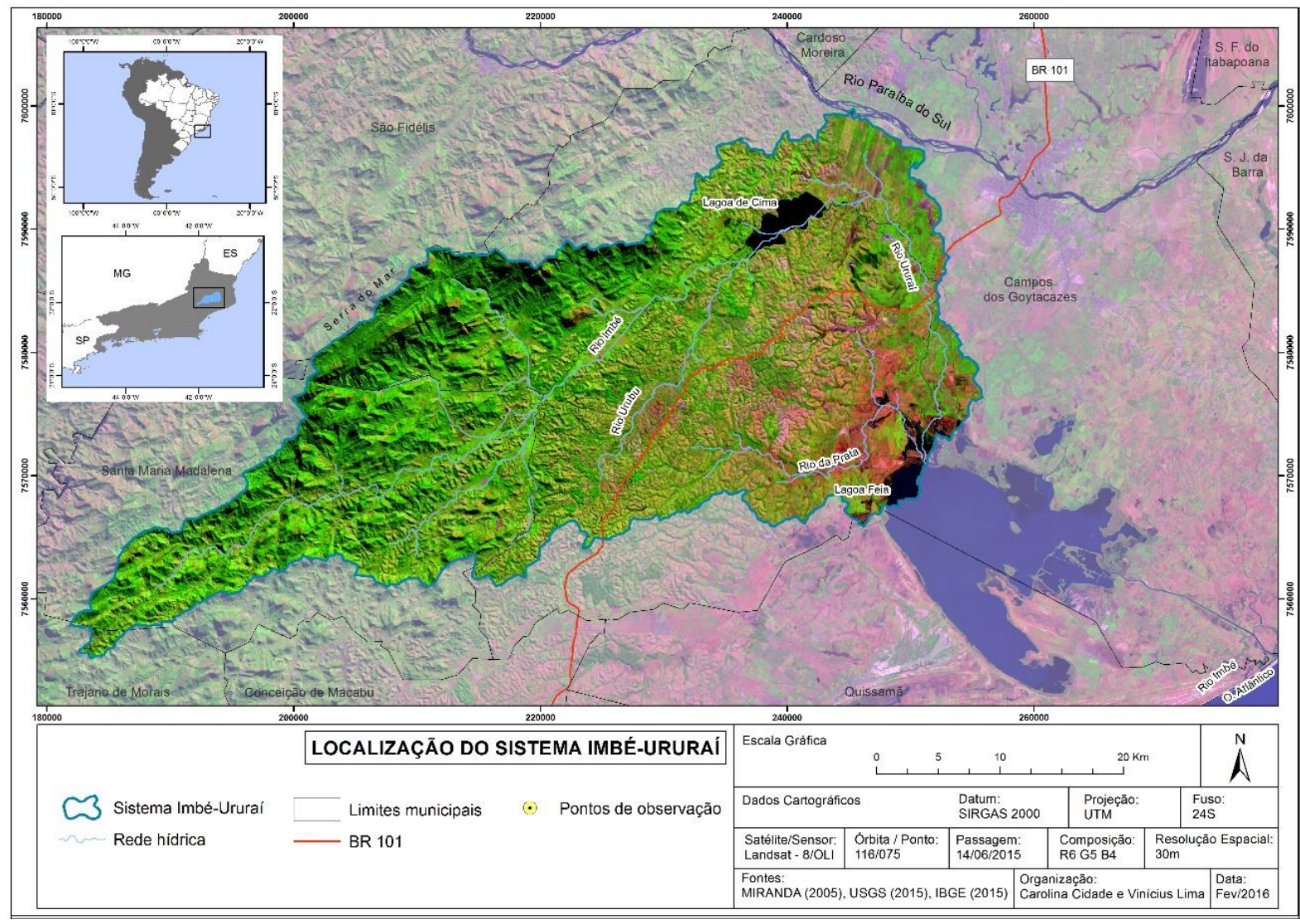

Figura 1 - Localização da bacia de drenagem do rio Imbé-Ururaí. Fonte: dos autores. 
Tomigana (2009) diferencia os processos de inundação e enchente, definindo a enchente pela elevação do nível d'água no canal de drenagem devido ao aumento da vazão, atingindo a cota máxima do canal. Já a inundação é definida como o transbordamento do nível máximo da enchente, quando alcança a planície de inundação ou área de várzea.

No entanto, Jiménez (2009) define inundação como a cobertura temporária de uma área normalmente não coberta por água, considerando inundações de rios, enxurradas e cursos de água efêmeros, além e inundações marítimas em zonas costeiras, não incluindo as inundações em redes pluviais.

Mesmo reconhecendo a importância da diferenciação dos dois processos (inundação e enchente), a inundação neste trabalho será tratada com a perspectiva de Jiménez (2009), como uma área preenchida por água de natureza hidrometeorológica, podendo associar-se à intervenções antrópicas no âmbito de uma bacia de drenagem, sem distinguir sua tipologia, como aquela feita por Tomigana (2009).

Para tanto, assumiu-se os seguintes questionamentos motivadores para este trabalho: Quais os mais expressivos usos da terra na área de estudo no ano de 2015? Quais os usos da terra efetivamente sujeitos aos efeitos das inundações? Como objetivo central, busca-se, com auxílio das geotecnologias, entender os processos de inundações que ocorrem na bacia de drenagem do rio Imbé-Ururaí atentando para os usos da terra sujeitos a este fenômeno no ano de 2015.

\section{METODOLOGIA}

\subsection{Aquisição de dados cartográficos, orbitais, interferométricos e pluviais}

Os produtos orbitais (imagens de satélite) foram adquiridos junto ao United States Geological Survey (USGS). Os anos selecionados foram 2009 e 2015 (Tabela 1), respectivamente em períodos úmido e seco, para identificação do evento de inundação mais extremo (2009) e os usos inundáveis (2015). Para que fosse realizada a escolha do ano de 2009, foi realizada pesquisa com toda a série histórica do satélite/sensor Landsat - 5/TM, que desde meados da década de 1980 fornece imagens, hoje obtidas gratuitamente junto ao USGS ou no Instituto Nacional de Pesquisas Espaciais - INPE.

\begin{tabular}{c|c|c|c|c|c}
\hline Satélite & Sensor & Órbita/Ponto & Data & Resolução & Fonte \\
\hline \multirow{2}{*}{ LANDSAT 5 } & TM & \multirow{2}{*}{$216 / 075$} & $05 / 02 / 2009$ & \multirow{2}{*}{$30 \mathrm{~m}$} & USGS \\
& & & $14 / 06 / 2015$ & & \\
\hline LANDSAT 8 & OLI & & & & \\
\hline
\end{tabular}

Tabela 1: Produtos orbitais. Fonte: Org. pelos autores. 
Os dados cartográficos e interferométricos foram adquiridos junto ao Instituto Brasileiro de Geografia e Estatística (IBGE). Para a espacialização do processo evolutivo de Uso da Terra no Sistema ImbéUruraí foram utilizados os Planos de Informações (PIs) em formato Shapefile (Tabela 2).

Para identificação dos eventos de maior precipitação, foram utilizados dados pluviométricos, em escala temporal de uma normal climatológica (1985 a 2015), disponibilizados pelo Instituto Nacional de Meteorologia (INMET) e da estação meteorológica da Universidade Federal Rural do Rio de Janeiro (UFRRJ) campus Campos dos Goytacazes.

\begin{tabular}{|l|c|l|l|l|l}
\hline $\begin{array}{l}\text { Dados Cartográficos e } \\
\text { Interferométricos }\end{array}$ & Datum & Projeção & Fonte & Data & Escala \\
\hline $\begin{array}{l}\text { Brasil.shp } \\
\text { Municípios.shp }\end{array}$ & $\begin{array}{c}\text { SIRGAS } \\
2000\end{array}$ & UTM & IBGE & 2010 & $1: 32.000 .000$ \\
\hline
\end{tabular}

Tabela 2: Produtos Cartográficos e Interferométricos. Fonte: Org. pelos autores.

\subsection{Processamento Digital de Imagens}

Para o tratamento das imagens orbitais, foi utilizada a técnica de ajuste da iluminação das mesmas através do realce para cada período descrito. Ainda neste contexto, utilizou-se também a técnica de composição de imagens (composite bands), com a composição RGB. Todas as técnicas de manipulação/confecção dos mapas, foram feitas no software ArcGIS 10.1. É bom ressaltar que, após a composição das imagens, foram considerados os elementos básicos para a interpretação das mesmas, de acordo com Jensen (2009).

Além disso, devido ao deslocamento existente entre as informações raster e vetoriais, foi necessário utilizar a técnica de Georeferenciamento (Georeferencing) das imagens de satélites e posterior retificação das mesmas através dos Pontos de Controle Terrestres (PCTs). Em seguida, foi criada uma máscara da área de estudo e adjacências com um recorte da imagem através do comando Extract by mask.

O Processamento Digital de Imagens (PDI) objetivou a classificação do Uso e Cobertura da Terra, de acordo com o Manual Técnico de Uso da Terra (IBGE, 2013). No processo foi utilizado o método de classificação pixel a pixel, supervisionado de máxima verossimilhança (MaxVer).

Este método considera a ponderação das distâncias entre as médias dos valores dos pixels das classes, utilizando parâmetros estatísticos. Portanto, nesse tipo de classificação, cada pixel é destinado à classe que tem a mais alta probabilidade, isto é maior semelhança a partir de cálculos estatísticos (INPE, 2015). 
XVII Simpósio Brasileiro de Geografia Fisica Aplicada

I Congresso Nacional de Geografia Física

\section{OS DESAFIOS DA GEOGRAFIA FÍSICA NA FRONTEIRA DO CONHECIMENTO \\ Instituto de Geociências - Unicamp \\ Campinas - SP \\ 28 de Junho à 02 de Julho de 2017}

Para isso, deve-se fazer uma ampla seleção de pixels para amostra de treinamento da classe. É importante também que a área de análise seja conhecida pelo analista para que a distribuição das classes e a seleção de amostras de treinamento possa ser o mais eficiente possível (CRÓSTA, 1993). A Figura 2 apresenta o fluxograma com as principais etapas, bem como os comandos chaves na elaboração dos mapas.

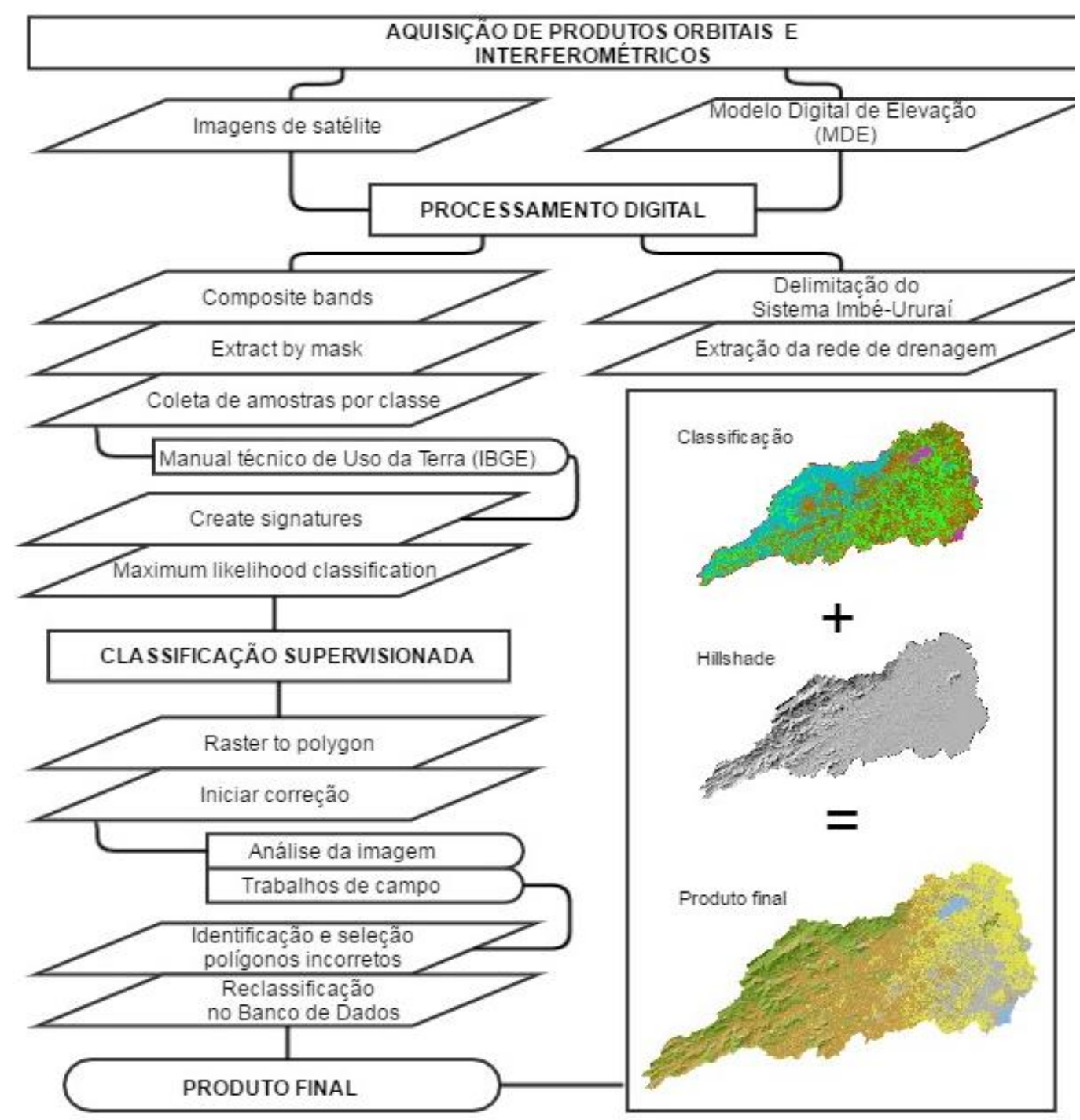

Figura 2: Principais etapas na elaboração dos mapas de uso da terra. Fonte: Org. pelos autores.

Após a realização das etapas anteriores foi possível realizar o cruzamento dos dados obtidos de modo a identificar os usos inundáveis. Para isso, foi extraída a área da maior mancha de inundação identificada dos últimos trinta anos e, em seguida, foi sobreposta aos Usos da Terra classificados anteriormente.

\subsection{Unidades de escala e Atividades de Campo}

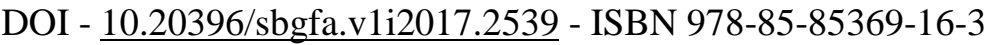


O IBGE (2013) indica a escala de mapeamento, unidades de mapeamento, a natureza da informação básica e nomenclatura como princípios básicos na estruturação do sistema de classificação de Uso da Terra. Ressalta ainda, a importância do Trabalho de Campo e reconhecimento da área para a interpretação, análise e registro das observações da paisagem com a finalidade de classificação e espacialização de Uso e Cobertura da Terra.

Os Trabalhos de Campo realizados, deram suporte para a representação de objetos espacialmente delimitáveis num trabalho conjunto de sensoriamento remoto e reconhecimento da área de estudo. Sobre isso, a Cartografia de Paisagem atende à necessidade de delimitação morfológica onde, o número de pontos observados devem variar mediante a escala trabalhada (CAVALCANTI, 2014). Da mesma forma, o produto final será apresentado com escala de 1:250.000 por ser considerado adequada para visualização de todo o sistema.

\section{RESULTADOS E DISCUSSÕES}

\subsection{Mapeamento dos usos da terra na bacia de drenagem do rio Imbé-Ururaí (2015)}

Dentre os usos apresentados no Manual de Uso da Terra do IBGE (2013), adotando-se o segundo nível taxonômico, foram identificados na área de estudo, no ano de 2015: águas continentais, culturas temporárias, área florestal, áreas de mineração, pastagens, áreas descobertas e área urbana (Figuras 3 e 4). A variação espacial desses usos foi observada a partir de sensoriamento remoto e apresentada após classificação supervisionada. 


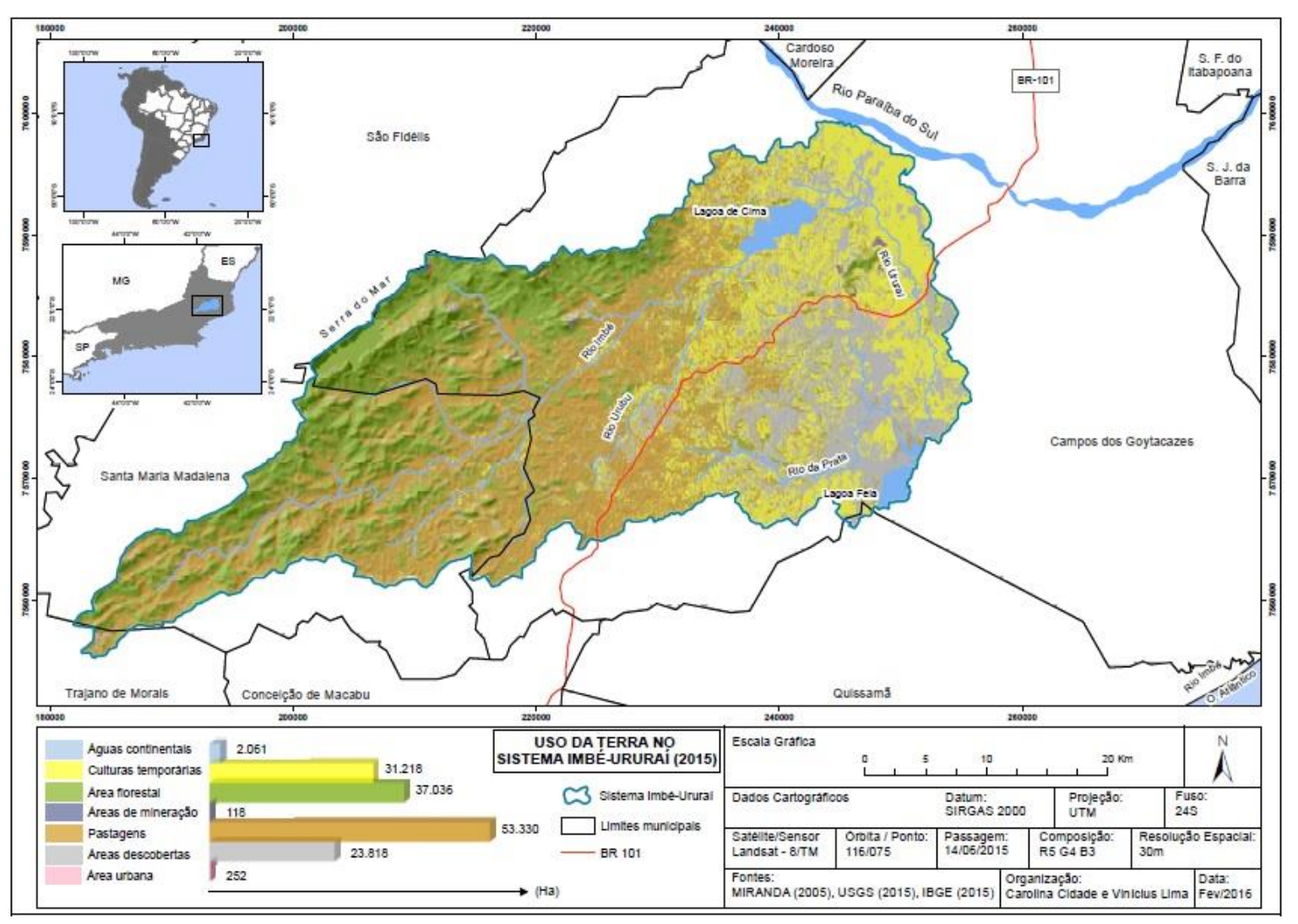

Figura 3: Uso da terra na bacia de drenagem do rio Imbé-Ururaí em 2015. Fonte: Dos autores.

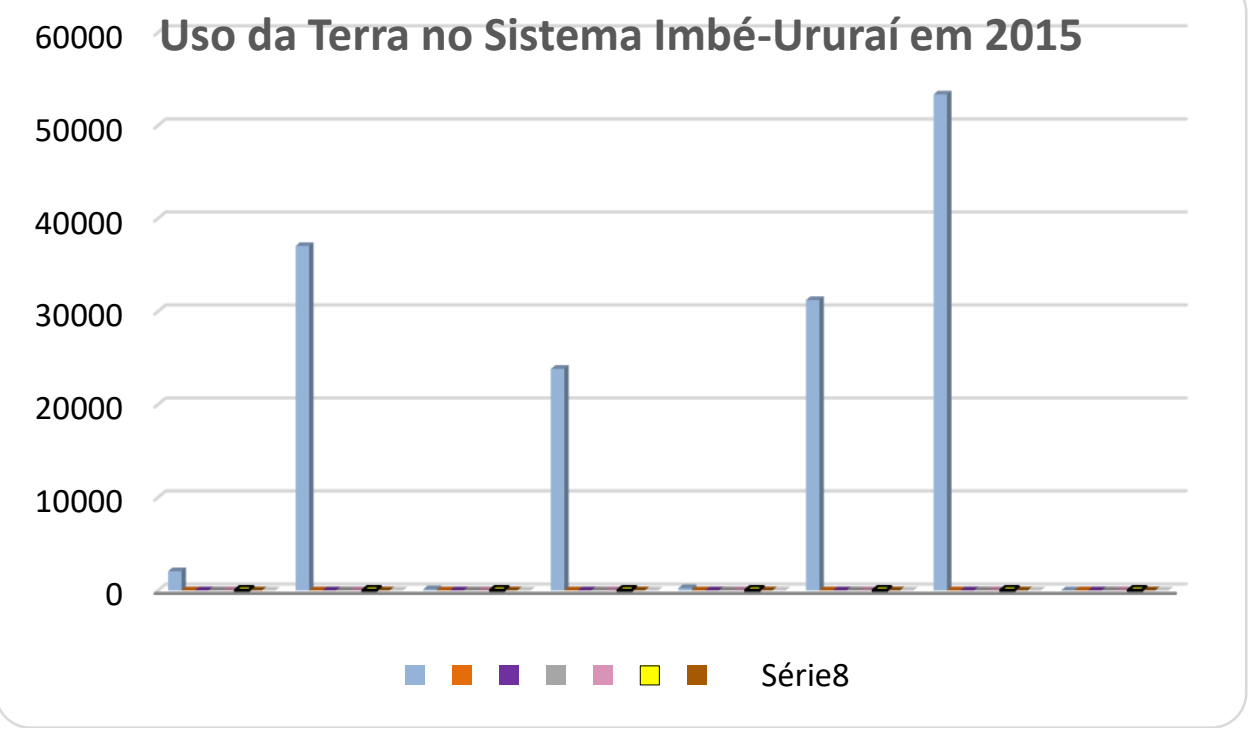

Figura 4 - áreas em hectares (ha) dos usos da terra na bacia de drenagem do rio Imbé-Ururaí. Fonte: Org. pelos autores.

A partir do exposto, compreende-se que a classe "pastagens" é responsável por abranger a maior área da bacia, estando distribuída, como indicam Lima e Coelho (2016) e Cidade (2016) sobre o domínio morfoestrutural da bacia sedimentar cenozoica, tendo pouca ocorrência nas paisagens escarpadas características do domínio do cinturão orogênico do Atlântico Sul. Para estes autores, pautados em 
outras referências bibliográficas, essa configuração espacial se dá em função das atividades humanas que foram desenvolvidas desde o processo de colonização. Concluem alertando que, ao contrário do que recorrentemente dizem, o município de Campos hoje possui em suas áreas maior presença de pasto em detrimento da cana-de-açúcar.

Com 37.036 hectares, encontra-se a segunda classe de maior ocorrência espacial. Sua representatividade se dá, sobretudo, pela presença de uma unidade de conservação de proteção integral. Trata-se do Parque Estadual do Desengano (PED), criado pelo Decreto-lei Estadual no 250 de 13 de abril de 1970. O PED encontra-se sobre a morfoestrutura do cinturão orogênico, e representa o maior fragmento contínuo de mata atlântica preservada no estado do Rio de Janeiro.

Além do PED, foram instauradas as Áreas de Preservação Ambiental (APA) da Lagoa de Cima (Lei Municipal $n^{\circ}$ 5.394/92) e Waldeir Gonçalvez - Serra do Itaóca (Lei Municipal nº 8.424/13), sendo a primeira um dos elementos principais do sistema hídrico apresentado, abrangendo, de acordo com o inciso IV e V, uma faixa de 30 metros medidos horizontalmente a partir do nível mais alto das águas e os leitos e margens dos afluentes e efluentes da lagoa, numa extensão de 500 metros a partir foz ou da nascente dos mesmos.

Em relação aos outros corpos hídricos do sistema, são protegidos por lei as Áreas de Preservação Permanente, onde fica determinada para rios com largura de até 10 metros uma faixa de protegida de 30 metros e para rios entre 10 e 50 metros de largura, é previsto uma faixa de 50 metros de proteção. Sendo assim, no caso do Sistema, suas APPs devem variar entre 30 e 50 metros de largura.

As terceira e quarta classes de maior ocorrência espacial são, respectivamente, culturas temporárias e áreas descobertas. Como cultura temporária assume-se para este trabalho a cana-de-açúcar. Ela se distribui sobre a planície holocênica e nos fundos de vale do grupo Barreirras. Já as áreas descobertas, entendida aqui como solos expostos, se encontram sobre toda a bacia de drenagem. Em campo foi possível identificar que essas áreas intercalam com a pastagem no decorrer do ano, o que pode gerar problemas na classificação supervisionada dependendo da quantidade de água disponível na superfície do planeta Terra, o que fortalece a importância do trabalho em campo.

As áreas urbanas e de mineração são as classes de menor ocorrência espacial. A primeira é representada, dentre outros, pelo bairro de Ururaí. Para Lima (2014), esta localidade concentra a maior população residente na bacia, totalizando 7.173 habitantes, distribuídos em 2.920 imóveis, muitos dos quais sujeitos aos efeitos das inundações. Já a mineração, outra classe, é uma atividade econômica que, em função da escala de mapeamento adotada, foi pouco representada. A despeito da limitação 


\section{OS DESAFIOS DA GEOGRAFIA FÍSICA NA FRONTEIRA DO CONHECIMENTO \\ Instituto de Geociências - Unicamp \\ Campinas - SP \\ 28 de Junho à 02 de Julho de 2017}

técnica, em campo foi observado atividade mineradora em alguns pontos, como por exemplo no maciço do Itaoca. Os usos da terra são apresentados na Figura 5.
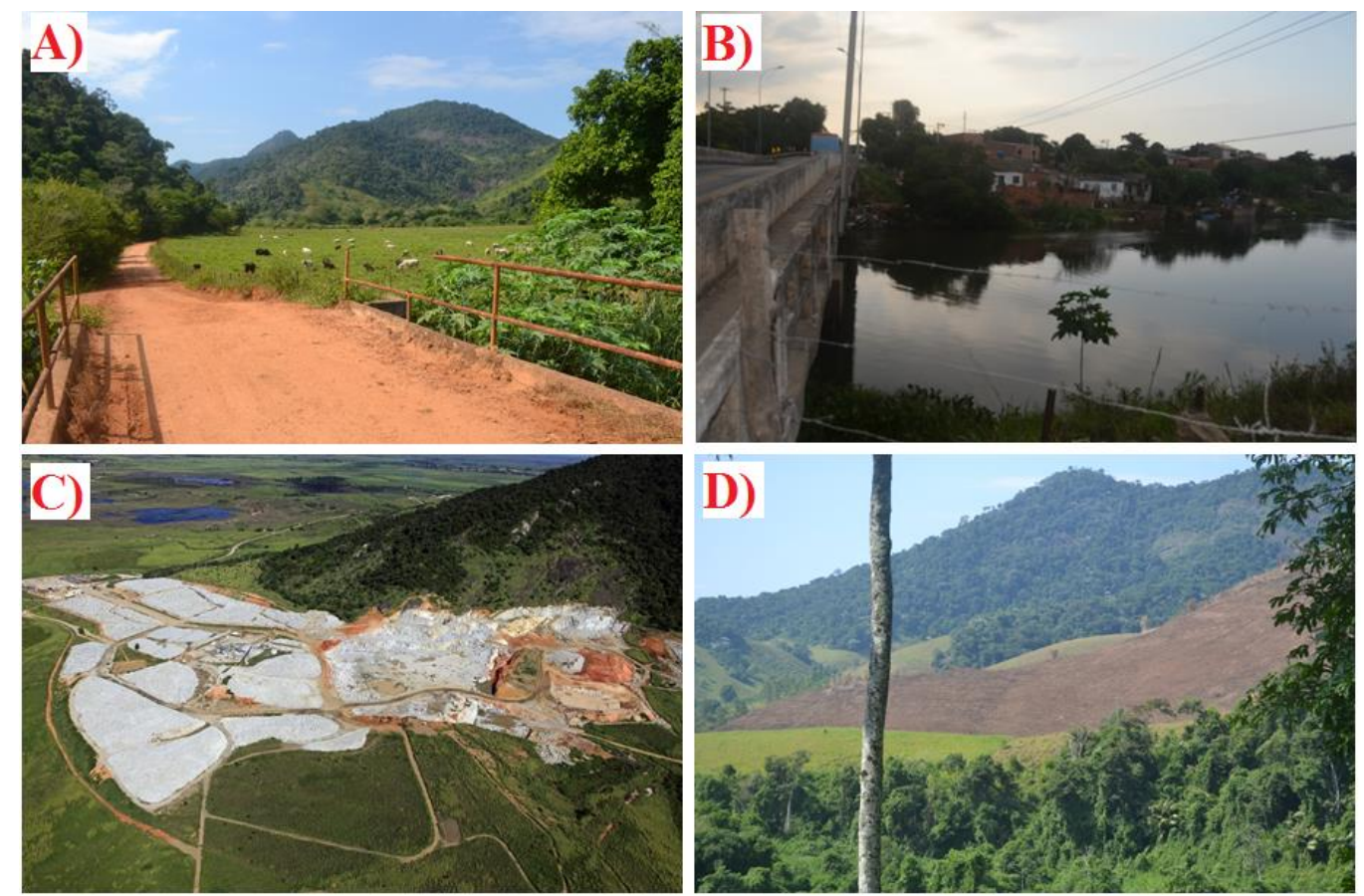

Figura 5: A) Pasto com criação de gado em área de várzea; B) Bairro de Ururaí às margens da BR101; C) Atividade mineralógica no maciço do Itaóca e; D) Área após a queima da cana-de-açúcar. Fonte: A, B, e D dos autores; C - Blog do Roberto Moraes.

\subsection{Identificação e mapeamento da maior inundação entre os anos de 1985 e 2015}

A partir do levantamento de dados pluviométricos e análise das imagens de satélite, concluiu-se que o ano de maior mancha de inundação foi o de 2009. De acordo com regionalização apresentada por André et. al., (2008), a área de estudo se enquadra na região 6, correspondente ao Norte do estado do Rio de Janeiro, com média de precipitação anual variável entre 766 a $945 \mathrm{~mm}$. De acordo com Para os autores a precipitação pluviométrica apresenta um padrão crescente do litoral em direção ao continente, na região onde localiza-se a bacia do rio Imbé-Ururaí.

A maior mancha de inundação dos últimos trinta anos ocupou uma área de aproximadamente 5.926 hectares (Tabela 3). Ao observar o tamanho do espelho d'àgua nos outros anos, percebeu-se uma variação de até 50\% a mais de área ao comparar 2009 com os outros anos analisados. Portanto, ao se considerar a área de alcance da água em períodos de cheia extrema, é previsível o fato de que os usos espacialmente próximos ao curso do rio Imbé-Ururaí serão atingidos de forma direta com as inundações.

\begin{tabular}{l|l|l|l|l|l}
\hline Uso x Ano & 1985 & 1995 & 2005 & $\mathbf{2 0 0 9}$ & 2015 \\
\hline
\end{tabular}


XVII Simpósio Brasileiro

de Geografia Fisica Aplicada

I Congresso Nacional

de Geografia Física

\section{OS DESAFIOS DA GEOGRAFIA FÍSICA NA FRONTEIRA DO CONHECIMENTO \\ Instituto de Geociências - Unicamp \\ Campinas - SP \\ 28 de Junho à 02 de Julho de 2017}

\begin{tabular}{l|l|l|l|l|l} 
Água (ha) & 2.024 & 1.972 & 2.362 & $\mathbf{5 . 9 2 6}$ & 2.050 \\
\hline
\end{tabular}

Tabela 3: Área ocupada pela água no Sistema Imbé Ururaí. Fonte: Org. dos autores.

Lima e Coelho (2016) identificaram que, a despeito das medidas-soluções para a contenção das inundações na área de estudo (construção de diques, canais, dragagem de canais, etc), a mesma encontra-se sobre constante potencial inundável, sobretudo nos fundos de vale dos Tabuleiros Terciários e na extensa Planície Quaternária sobre a Bacia Sedimentar Cenozoica.

A mancha de 2009, assim como os outros usos, também pode ser associada aos níveis pluviométricos do verão (período úmido). A média do nível de pluviosidade dentro da série temporal trabalhada é de $912 \mathrm{~mm} /$ ano. Ao observar os anos anteriores a 2009, é possível verificar o aumento dessa média anual desde 2004, cinco anos antes da cheia em questão (Tabela 4), alcançando sua 'cota' máxima em 2008 quando atingiu $1635 \mathrm{~mm}$ de chuva.

\begin{tabular}{c|c|c|c|c|c|c|c}
\hline Período & $\mathbf{1 9 8 5 - 2 0 1 5}$ & $\mathbf{2 0 0 4}$ & $\mathbf{2 0 0 5}$ & $\mathbf{2 0 0 6}$ & $\mathbf{2 0 0 7}$ & $\mathbf{2 0 0 8}$ & $\mathbf{2 0 0 9}$ \\
\hline $\begin{array}{c}\text { Volume } \\
(\mathbf{m m})\end{array}$ & 912,4 & $1.147,8$ & $1.347,0$ & 866,2 & $1.233,6$ & $1.635,6$ & $1.027,5$ \\
\hline
\end{tabular}

Tabela 4: Média de precipitação nos anos que antecederam a mancha de inundação de 2009. Fonte: (UFRRJ, 2016). Org. dos autores.

Assume-se que a mancha de inundação de 2009 não é resultado somente da pluviosidade daquele ano, mas sim da saturação de água no solo e a consequente dificuldade de infiltração, que já o mesmo encontrava-se encharcado, no período em que o espelho d'água atingiu o nível máximo registrado.

Além da pluviosidade é possível relacionar esse acontecimento também à fatores humanos, como por exemplo a existência de diques construídos ao longo do sistema para facilitar a drenagem das áreas de cultivo ao longo do século XX pelo Departamento Nacional de Obras e Saneamento (DNOS), o que nesse momento dificultou o escoamento da água e medidas de restauração foram tomadas, como a implosão de diques, para que o bairro de Ururaí, que ficou grande parte inundado, pudesse sair do estado de calamidade (LIMA E COELHO, 2016).

Tendo em vista a elevada escassez de dados ambientais no Brasil, como série histórica de vazões de longos períodos para área de estudo, o uso de dados de precipitação, associados aos produtos orbitais tornam-se fundamentais para estudos que visem gerar cenários futuros. Neste sentido, extraiu-se a mancha de inundação de 2009 e projetou-se a mesma sobre os usos da terra de 2015 , entendendo que este cenário poderá ajudar na geração de modelos de previsão de inundações pautados em outras 


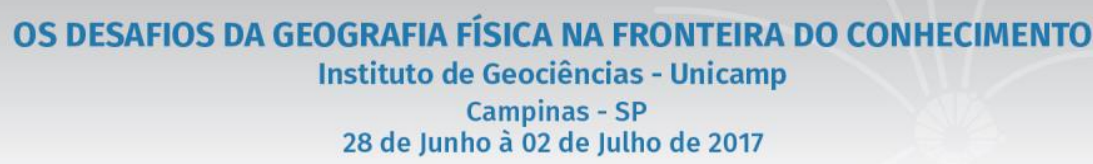

variáveis, a exemplo da morfometria, da estrutura e da permeabilidade. Ao utilizar da ferramenta "Clip", obteve-se os resultados apresentados na Figura 7.

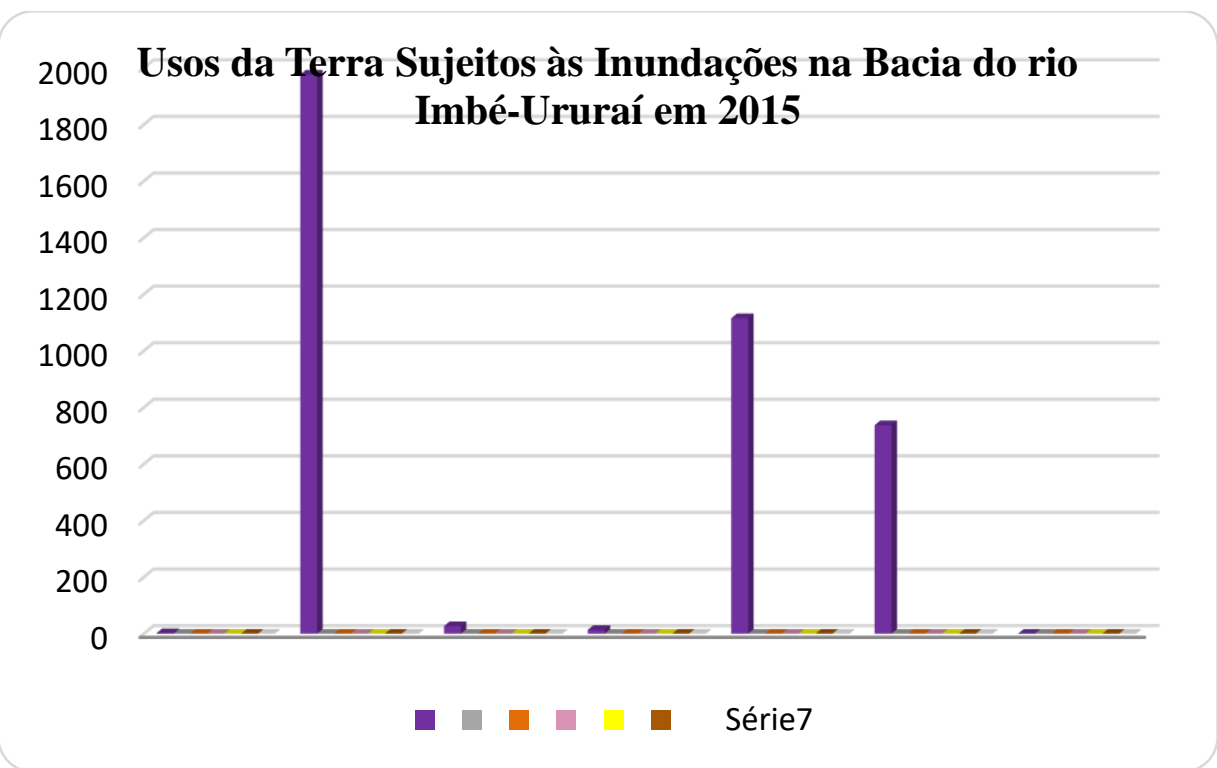

Figura 7: Usos da terra sujeitos às inundações no ano de 2009. Fonte: Org. dos autores.

Nota-se que a classe mapeada como "áreas descobertas" é a maior atingida pelos efeitos das inundações. Esse fato se dá pelo atributo espacial de proximidade e devido a sua baixa hipsometria e declividade (LIMA E COELHO, 2016; CIDADE, 2016). Esta classe, juntamente a cana-de-açúcar (culturas temporárias) e as pastagens estão inseridas nos domínios morfoesculturais das planícies fluviomarinhas e das Colinas e Tabuleiros.

Do ponto de vista dos aspectos clinográficos, Cidade (2016) entende que as áreas atingidas pelas inundações ocupam os terrenos com declividade entre 0-3\% (plano) e 3-8\% (suave ondulado). Não havendo registros de eventos dessa natureza entre os intervalos de $20-45 \%$ (forte ondulado) e $45-75 \%$ (montanhoso). Importante ressaltar que, mesmo sendo uma bacia de drenagem essencialmente rural, os danos aos ao bairro de Ururaí (Figura 8) e às populações que habitam às áreas adjacentes da lagoa de Cima geram perdas de bens materiais e transtornos nas vias de transporte terrestre, sobretudo na BR-101, principal rodovia do país. 


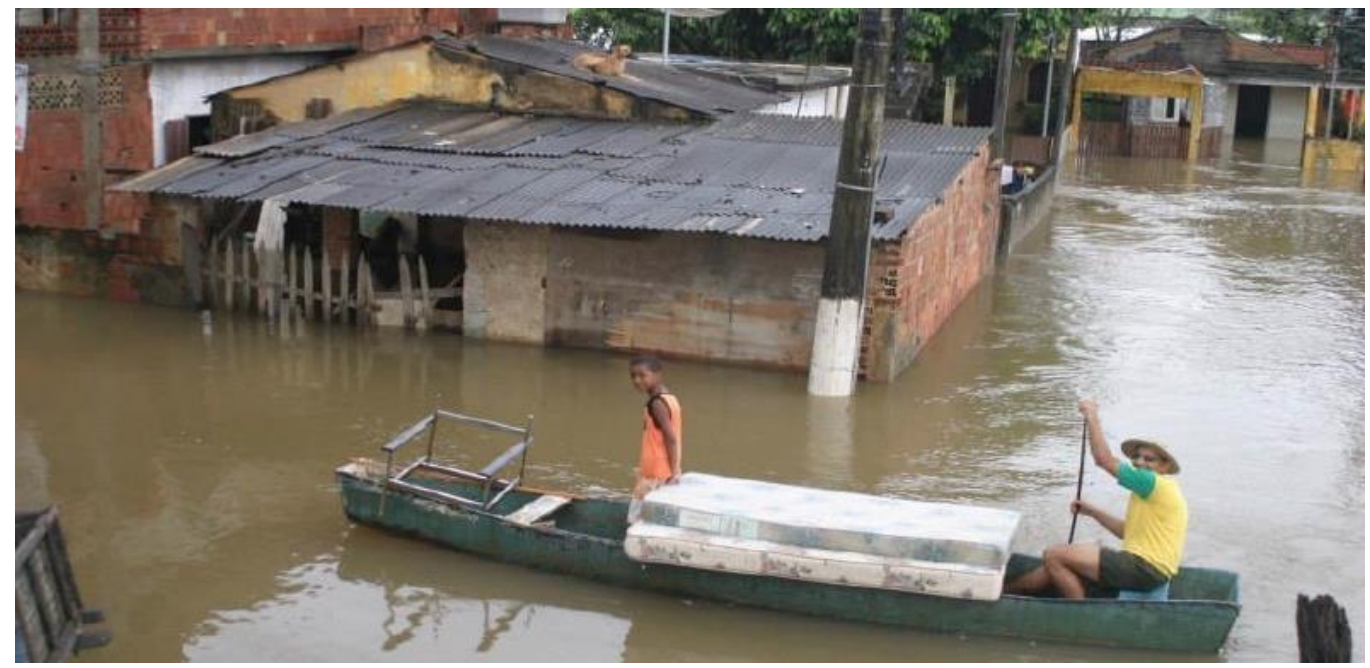

Figura 8: Moradores de Ururaí em situação de cheia no ano de 2009. Fonte: Blog do Roberto Moraes.

\section{CONCLUSÕES}

O uso da terra na bacia de drenagem do rio Imbé-Ururaí apresentou-se como majoritariamente rural. A pastagem, no ano de 2015, foi a classe de maior ocorrência espacial, seguida da cobertura vegetal representada, sobretudo, pelo Parque Estadual do Desengano e sua floresta ombrófila. A cultura da cana-de-açúcar também foi identificada como uma feição de grande representatividade. A despeito da tradição norte-fluminense, com destaque ao município de Campos dos Goytacazes, no cultivo da canade-açúcar, os resultados indicam que este não é o principal uso, mas sim a pastagem. Os terrenos quaternários (planícies flúvio-marinhas) e os fundos de vale dos interflúvios do Grupo Barreiras são morfologias, em função da sua baixa altitude e declividade, frequentemente sujeitos às inundações, tendo, respectivamente, nas classes de áreas descobertas, culturas e pastagens as maiores probabilidades.

Maiores estudos de monitoramento das séries históricas de vazões são necessários, não havendo estações ativas com dados atualizados para a área de estudo desde o Regime Militar no Brasil. A geração de modelos que visem o prognóstico aos efeitos das inundações através do cruzamento de informações de base física e social, como a morfometria, morfologia, precipitação, permeabilidade e o uso da terra são imprescindíveis no suporte ao ordenamento territorial-ambiental.

\section{BIBLIOGRAFIA}

ANDRÉ et al. Identificação De Regiões Pluviometricamente Homogêneas No Estado Do Rio De Janeiro, Utilizando-Se Valores Mensais. Revista Brasileira de Meteorologia, v.23, n.4, 501, 2008.

CAVALCANTI, L. C. Cartografia de paisagens: fundamentos. Oficina de Textos, 2014. 
CIDADE, C. de A. S. Mudança no uso da terra no sistema Imbé-Ururaí entre 1985-2015: um estudo sobre a potencialidade das inundações. Monografia de Graduação. Universidade Federal Fluminense - UFF (PUCG), Campos dos Goytacazes/RJ, 2016.

COELHO, A. L. N. Alterações hidrogeomorfológicas no médio baixo Rio Doce/ES. Tese de doutorado. Universidade Federal Fluminense - UFF, Niterói, 2008.

CROSTA A. P. Processamento Digital de Imagens de Sensores Remotos. IG/UNICAMP, Campinas - SP. (1993).

CUNHA, C. D.; CUNHA, S. B. Inundações urbanas e a impermeabilização do solo: avaliação do compartimento da bacia hidrográfica da Baía de Guanabara. Revista Equador, v. 4, p. 783-790, 2015.

FLORENZANO, T. G. Geomorfologia, conceitos tecnologias atuais. Editora: Oficina de textos, São Paulo, 2008, 318p.

INSTITUTO NACIONAL DE METEOROLOGIA - INMET. Banco de Dados Meteorológico para Ensino e Pesquisa. Disponível em: http://www.inmet.gov.br/portal/index.php?r=bdmep/bdmep Acessado em: 09 jul. 2016.

INSTITUTO NACIONAL DE PESQUISAS ESPACIAIS - INPE. DIVISÃO E PROCESSAMENTO DE IMAGENS. Tutorial de classificação de imagens. São Paulo, 2015.

JENSEN, J. R. Sensoriamento Remoto do Ambiente: uma perspectiva em Recursos Terrestres. Traduação de J. C. N. Epiphanio. São José dos Campos, SP: Parênteses, 2009.

JIMENÉS, J. A. Guidelines on coastal flood hazard mapping. Sixth framework programme. U K., 2009.

LIMA, V. S. Variação Espaço-Temporal do Espelho D’água da Lagoa Feia, RJ. 2014. Dissertação (Mestrado em Geografia) - Universidade Federal do Espírito Santo, Vitória/ES. 2014.

LIMA, V. S.; COELHO, A.L.N. Impactos Antrópicos e Mudanças na Paisagem: Um Estudo Sobre a Lagoa Feia/Brasil. 1. ed. Saarbrücken: Novas Edições Acadêmicas, Alemanha, 2016. 
MIRO, J. S. L. Metodologia para a elaboração do zoneamento das áreas sujeitas à inundação na Baixada Campista/Norte Fluminense - Rio de Janeiro. Dissertação (Mestrado em Engenharia Ambiental) - Instituto Federal de Educação, Ciência e Tecnologia Fluminense. Campos dos Goytacazes-RJ, 2009.

SALGADO, C. M. et al. Caracterização espaço-temporal da chuva como subsídio à análise de episódios de enchentes no município de Angra dos Reis, RJ. In: Geosul, Florianópolis, v. 22, n. 44, p 7-26, jul./dez. 2007

TOMIGANA, L. K. Desastres naturais: Por que ocorrem? In: TOMIGANA, L. K. SANTORO, J. E AMARAL,R. (orgs.). Desastres naturais: conhecer para prevenir. São Paulo, Instituto Geológico, 2009.

UNITED STATES GEOLOGICAL SURVEY - USGS. Aquisição de imagens Landsat 5 e Landsat 8.

UNIVERSIDADE FEDERAL RURAL DO RIO DE JANEIRO - UFRRJ. Dados de pluviosidade. Campos dos Goytacazes, 2016. 